\title{
LA-UR-12-22042
}

Approved for public release; distribution is unlimited.

Title: $\quad$ Draft report on melt point as a function of composition for urania-based systems

\author{
Author(s): $\quad$ Valdez, James A \\ Byler, Darrin D
}

Intended for:

\author{
L3 milestone report for FC R\&D program \\ Report
}

\section{- LosAlamos}

\author{
EST. 1943
}

Disclaimer:

Los Alamos National Laboratory, an affirmative action/equal opportunity employer,is operated by the Los Alamos National

Security, LLC for the National NuclearSecurity Administration of the U.S. Department of Energy under contract DE-AC52-06NA25396.

By approving this article, the publisher recognizes that the U.S. Government retains nonexclusive, royalty-free license to

publish or reproduce the published form of this contribution, or to allow others to do so, for U.S. Government purposes.

Los Alamos National Laboratory requests that the publisher identify this article as work performed under the auspices of the

U.S. Departmentof Energy. Los Alamos National Laboratory strongly supports academic freedom and a researcher's right to publish; as an institution, however, the Laboratory does not endorse the viewpoint of a publication or guarantee its technical correctness. 


\title{
Draft report on melt point as a function of composition for urania-based systems
}

\author{
Prepared for \\ U.S. Department of Energy \\ FCRD Program \\ By James Valdez \\ and Darrin Byler \\ National Laboratories \\ June 7,2012




\section{DISCLAIMER}

This information was prepared as an account of work sponsored by an agency of the U.S. Government. Neither the U.S. Government nor any agency thereof, nor any of their employees, makes any warranty, expressed or implied, or assumes any legal liability or responsibility for the accuracy, completeness, or usefulness, of any information, apparatus, product, or process disclosed, or represents that its use would not infringe privately owned rights. References herein to any specific commercial product, process, or service by trade name, trade mark, manufacturer, or otherwise, does not necessarily constitute or imply its endorsement, recommendation, or favoring by the U.S. Government or any agency thereof. The views and opinions of authors expressed herein do not necessarily state or reflect those of the U.S. Government or any agency thereof. 


\section{ABSTRACT}

This report documents the testing of a urania $\left(\mathrm{UO}_{2.00}\right)$ sample as a baseline and the attempt to determine the melt point associated with 4 compositions of urania-ceria and urania-neodymia pseudo binaries provided by ORNL, with compositions of $95 / 5$, and $80 / 20$ and of $(\mathrm{U} / \mathrm{Ce}) \mathrm{O}_{2.00}$ and $(\mathrm{U} / \mathrm{Nd}) \mathrm{O}_{2.00}$ in the newly developed ceramic melt point determination system. A redesign of the system using parts fabricated from tungsten was undertaken in order to help prevent contamination and tungsten carbide formation in the crucibles. The previously developed system employed mostly graphite parts that were shown to react with the sample containment black-body crucible leading to unstable temperature readings and crucible failure, thus the redesign. Measured melt point values of $\mathrm{UO}_{2.00}$ and $\mathrm{U}_{0.95} \mathrm{Ce}_{0.05} \mathrm{O}_{2.00}$, $\mathrm{U}_{0.80} \mathrm{Ce}_{0.20} \mathrm{O}_{2.00}, \mathrm{U}_{0.95} \mathrm{Nd}_{0.05} \mathrm{O}_{2.00}$ and $\mathrm{U}_{0.80} \mathrm{Nd}_{0.20} \mathrm{O}_{2.00}$ were measured using a 2-color pyrometer. The value measured for $\mathrm{UO}_{2.00}$ was consistent with the published accepted value $2845^{\circ} \mathrm{C} \pm 25^{\circ} \mathrm{C}$, although a wide range of values has been published by researchers and will be discussed later in the text. For comparison, values obtained from a published binary phase diagram of $\mathrm{UO}_{2}-\mathrm{Nd}_{2} \mathrm{O}_{3}$ were used for comparison with our measure values. No literature melt point values for comparison with the measurements performed in this study were found for $(\mathrm{U} / \mathrm{Ce}) \mathrm{O}_{2.00}$ in our stoichiometry range. 


\section{CONTENTS}

ABSTRACT iii

ACRONYMS .vi

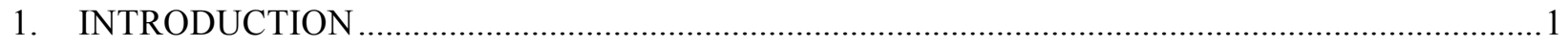

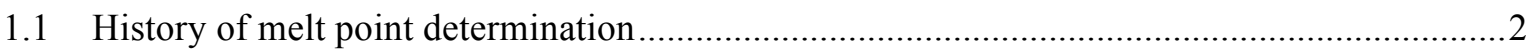

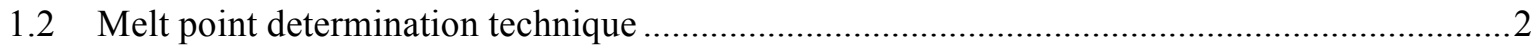

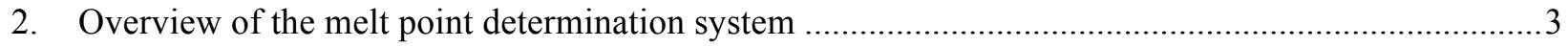

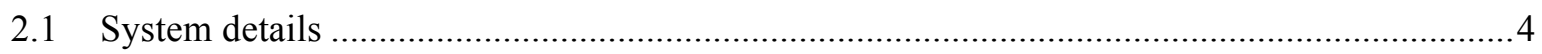

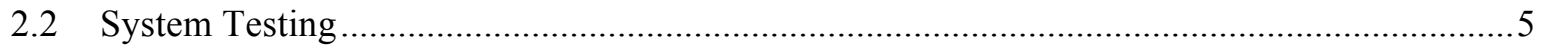

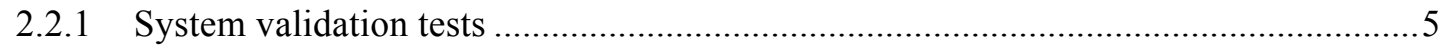



2.3.1 Fabrication of pseudo binary U-Ce-O and U-Nd-O test materials ............................. 8

2.4 Experimental details and results obtained from measurements of $\mathrm{U}_{2.00}, \mathrm{U}-\mathrm{Ce}-\mathrm{O}$ and

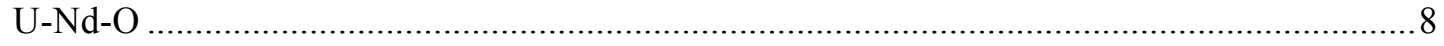

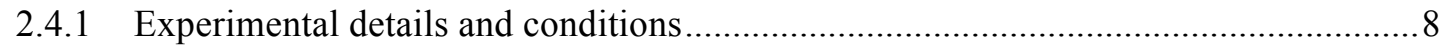

2.4.2 Experimental results obtained from measurements of $\mathrm{UO}_{2.00}$ and $\mathrm{U}-\mathrm{Ce}-\mathrm{O}$

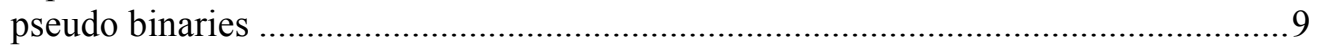

2.4.3 Experimental results obtained from measurements of $\mathrm{UO}_{2.00}$ and $\mathrm{U}-\mathrm{Nb}-\mathrm{O}$



3. Summary

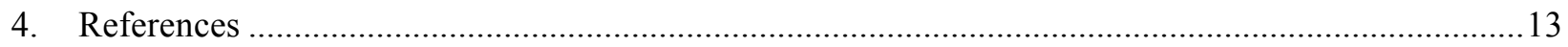

\section{FIGURES}

Figure 1. A plot obtained from literature values for melting points of $\mathrm{UO}_{2}$ from 1965 to 2006. The average value from these literatures values was calculated to be $\sim 3130 \mathrm{~K}\left(2857^{\circ} \mathrm{C}\right)$.................

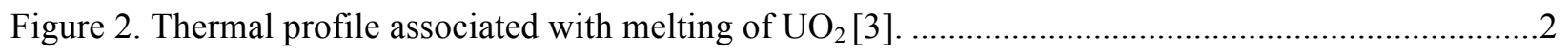

Figure 3. Diagram comparing a binary oxide systems thermo/compositional behavior to a melt



Figure 4. Illustration of a typical modern melt point apparatus..............................................................

Figure 5. Melt point determination system used by Komatsu et al. [3] ...................................................

Figure $6(a, b)$. Figure 6 a shows a 3-D sectional rendering of the melt point system heating assembly used in the melt point determination experiments and figure $6 \mathrm{~b}$ is a photo of the actual system.

Figure 7. A Binary phase diagram of $\mathrm{HfO}_{2}-\mathrm{MgO}$ showing the monoclinic to tetragonal and the tetragonal to cubic transformation temperatures highlighted with red boxes. 
Figure 8(a,b) Figure 8a shows heating curve plots obtained from two independent tests showing the temperatures in which the $\mathrm{m}-\mathrm{t}$ and $\mathrm{t}-\mathrm{c}$ transformations occur. Figure $8 \mathrm{~b}$ shows the result of a melt point determination test. Results from both series of tests are in good agreement with the reported literature values.

Figure 9. Heating curve plots obtained from four ( 2 on Mo and 2 on $\mathrm{Nb}$ ) melt point determination experiments. The averaged measured values compare well with the [12] melt point values, specifically for $\mathrm{Mo}_{\text {measured }}-2619^{\circ} \mathrm{C}$ ) vs. $\mathrm{Mo}_{[12]}-2623^{\circ} \mathrm{C}$ and $\mathrm{Nb}_{\text {measured }}-2486^{\circ} \mathrm{C}$ vs. $\mathrm{Nb}_{[12]^{-}}-2477^{\circ} \mathrm{C}$.

Figure 10. A typical experimental voltage (power) heating profile used during melt point determination experiments.

Figure 11. Heating curves collected during melting point experiments on $\mathrm{UO}_{2.00}$ and the $\mathrm{U}-\mathrm{Ce}-\mathrm{O}$ test specimens.

Figure 12. Heating curves collected during melting point experiments on $\mathrm{UO}_{2.00}$ and the U-Nd-O test specimens.

Figure 13. Plot of a binary phase diagram showing the solubility of $\mathrm{Nd}_{2} \mathrm{O}_{3}$ in $\mathrm{UO}_{2}$. The phase diagram has a highlighted region in the composition range in which samples were measured in fulfillment of this report.

\section{TABLES}

Table 1. Tabulated values from the literature and measured data comparing of the transformation and melting temperatures.

Table 2. Table comparing literature values obtained from [16] with measure value collect during this investigation. The last row shows the difference between the two sets of values. 


\title{
ACRONYMS
}

\author{
$\mathrm{AC}-$ Alternating Current \\ Ar $/ 6 \% \mathrm{H}$ - Argon- $6 \%$ hydrogen \\ EAEC - European Atomic Energy Community \\ $\mathrm{HfO}_{2}-$ Hafnium dioxide/Hafnia \\ IR - Infrared \\ JAEA - Japan Atomic Energy Agency \\ LANL - Los Alamos National Laboratory \\ m-t - Monoclinic to Tetragonal \\ MDD- Modified Direct Denitration \\ $\mathrm{Nb}-$ Niobium \\ $\mathrm{Nd}$ - Neodymium \\ $\mathrm{O} / \mathrm{M}$ - Oxygen to Metal ratio \\ ORNL - Oak Ridge National Laboratory \\ RF - Radio Frequency \\ t-c - Tetragonal to Cubic \\ $\mathrm{UO}_{2}$ - Urania
}




\section{DRAFT REPORT ON MELT POINT AS A FUNCTION OF COMPOSITION FOR URANIA- BASED SYSTEMS}

\section{INTRODUCTION}

This report provides details of the development, validation, and preliminary melt point measurements of $\mathrm{UO}_{2.00}$, urania-ceria and urania-neodymia solid solutions provided by ORNL. Temperature measuring equipment reliability and testing of the system was performed on Niobium ( $\mathrm{Nb}$ ), Molybdenum (Mo) and on Hafnium dioxide $\left(\mathrm{HfO}_{2}\right)$. Comparison of the measured values collected on our system with results from published data revealed consistency between the two. Urania, urania-ceria and urania-neodymia melt point measurements were successfully made. Measurements on the urania-ceria solid solutions are discussed later in the text and are under further investigation due to the fact that no datasets were found during our literature survey for comparison.

Included in this report are the basic background information about the project, a brief history of the work in the US, a discussion of the variation in melt point values for urania and the results obtained from our measurements compared with available published values (if they exist).

With recent interest in higher burn-ups and deeper burns, the need to know how fission product evolution, oxygen-to-metal ratios $(\mathrm{O} / \mathrm{M})$, and composition affects the melting point of nuclear fuels to allow a sufficient safety factor in the design of the fuel and development of operational limits. Melt point values of "simple" systems such as pure $\mathrm{UO}_{2}$ have had a wide range of values reported, between $2400{ }^{\circ} \mathrm{C}$ and $2900{ }^{\circ} \mathrm{C}$ over the past 60 years with varying levels of error reported [1-9]. Much of this error may have been due to $\mathrm{O} / \mathrm{M}$ variations in the tested materials leading to very different melt point values, as well as the techniques used to attain the values. This broad range of melting point values are shown in Figure 1 from a literature survey in work by Kato et al. [8]. Based on this wide range of values, predictive models and calculations focused on safety criteria and the development of robust fuels with higher and more efficient burnups becomes problematic.

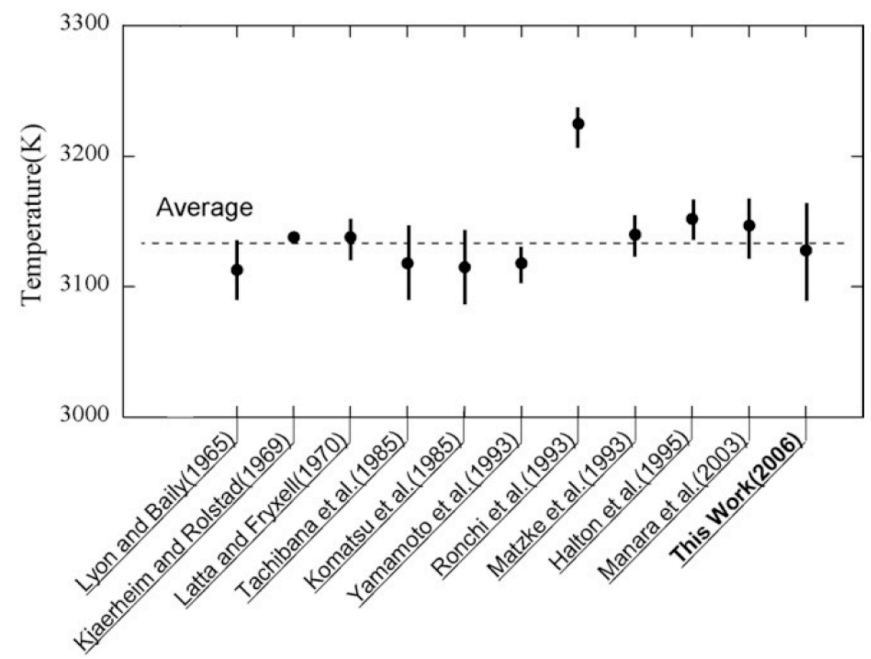

Figure 1. A plot obtained from literature values for melting points of $\mathrm{UO}_{2}$ from 1965 to 2006 . The average value from these literatures values was calculated to be $\sim 3130 \mathrm{~K}\left(2857^{\circ} \mathrm{C}\right)$. 


\subsection{History of melt point determination}

As previously stated, considerable effort has been placed on understanding the melting point behavior of $\mathrm{UO}_{2}, \mathrm{PuO}_{2} / \mathrm{UO}_{2}$ solid solutions and the effects of irradiation seen during burnup, followed by subsequent generation of fission products on these fuel materials. The General Electric Company (GE) starting in the early 1950s-1960s and ending in the mid 1970s, doing much of the early work performed by the US. After that time, much of the R\&D component of nuclear fuels development became stagnant up until recent interests focused on clean sustainable energy and energy futures. During this same time period, the EAEC (European Atomic Energy Community) and most recently the JAEA (Japan Atomic Energy Agency) continued to commit considerable resources on improving the knowledge base for fuel properties and characterization techniques, allowing for future advances in nuclear fuel and reactor design. This continued commitment to fuels development provided both EAEC and JAEA with a much larger database of information on which to base designs and improvements in the nuclear fuel arena. This prolonged research effort by the European community has lead to the US falling behind on fuels research related knowledge.

\subsection{Melt point determination technique}

The method chosen for melt point determination of bulk materials at high temperature is the thermal arrest technique. This technique is used for high melting point materials, typically using an induction heating system to either directly or indirectly heat a capsule with a very high melting point (tungsten $\sim 3400^{\circ} \mathrm{C}$ ), containing the sample material such as $\mathrm{UO}_{2}$, past the melting point while recording the temperature [10]. As the capsule is heated and the material inside starts to melt, there is a thermal lag in the temperature signal due to the endotherm associated with the phase transformation from solid to liquid. This lag in the thermal profile is well illustrated in figure 2 below for the melting of $\mathrm{UO}_{2}$ [3]. This phenomenon is illustrated schematically in figure 3. Figure 3 illustrates the temperature/composition behavior for a generic binary phase diagram of two oxide ceramics with different meting points, with lines extending out to a schematic representation of a typical melt point determination heating curve which illustrates a typical experiment. Because accurate temperature measurement of the capsule during these heating and cooling steps is critical, a method to consistently record the temperature profiles is necessary.

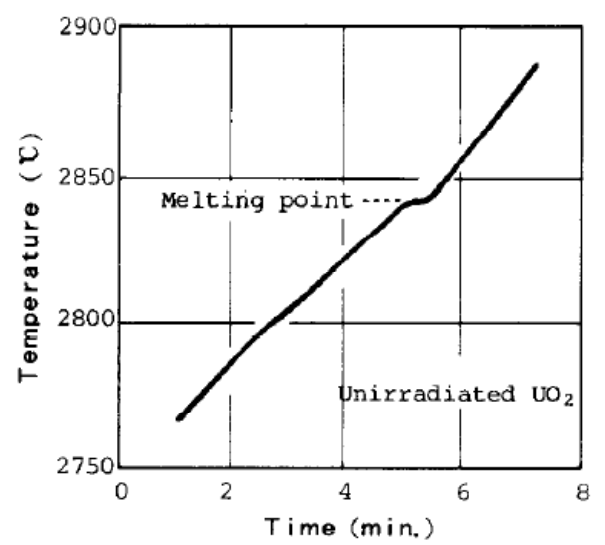

Figure 2. Thermal profile associated with melting of $\mathrm{UO}_{2}[3]$. 




Figure 3. Diagram comparing a binary oxide systems thermo/compositional behavior to an idealized melt point heating curve.

Ceramic nuclear fuels have high melting points $>2400{ }^{\circ} \mathrm{C}$, therefore common methods using standard thermocouple measurement techniques are unsuitable. Because of this limitation, non-contact methods are employed. The earliest methods used visual determination for the temperature of materials by referencing the brightness of a known light source against the brightness of the object being measured and could be several hundred degrees from the true value of the melting point due to oxidation, surface effects, etc. To remove some of the inaccuracy, Infrared (IR) pyrometers replaced thermocouples, but potential errors continued to exist due to the emissivity difference of various materials. To ensure accuracy, black body radiation sources were required to calibrate the instruments. Another, more precise method in which two narrow band IR signals that are very close in wavelength are compared against each other allowed for the removal of much of the inaccuracy due to emissivity and other effects. With these improvements in temperature measurement techniques, melting and solidification points of the materials can be more accurately determined and external factors corrected for.

\section{Overview of the melt point determination system}

The ceramic melt point determination system was designed based on research done in the early 60's by GE and work by EAEC and JAEA. Melt point determination systems in use today typically use a melting package consisting of a capsule to hold the materials to be tested, a susceptor to uniformly heat the capsule and couple to a high frequency AC voltage in a RF coil and a water cooled concentrator coil to concentrate the flux field of the RF coil onto the susceptor for better energy transfer efficiency. Additionally this allows for a protective enclosure. This is depicted in figure 4 below.

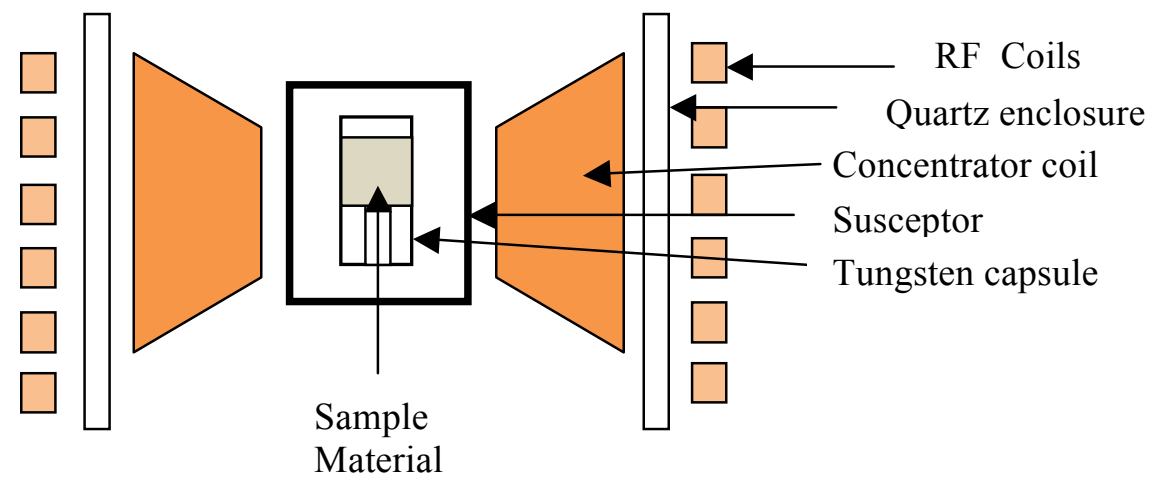

Figure 4. Illustration of a typical modern melt point apparatus. 
In addition to the melting package, there is an insulation package that allows management of the energy losses to the environment. The insulation package in the modern designs is a series of baffles using tungsten and other high melt point materials to reflect radiant heat back towards the susceptor and protects the end caps from exposure to very high temperatures. This is illustrated in figure 5 below.



Figure 5. Melt point determination system used by Komatsu et al. [3].

One of the concerns that were presented about this design was that the water-cooled current concentrator coil could be breached if a failure of the melt package occurred causing a release of steam and radioactive material at high temperature. Therefore to mitigate this possible problem a graphite susceptor and high temperature insulation was used. It was found that graphite reacted with the tungsten at high temperatures causing erratic temperature measurements and in some cases, crucible failure. Thus, the system was redesigned to approximate the water-cooled design, but due to power limitations, the current concentrator was removed and direct coupling to the tungsten crucible was used. This design will be illustrated in system details.

\subsection{System details}

After multiple system designs a final design was settled on. This design was chosen for several criteria, mainly, ease of loading sample crucibles, low contamination due to off gassing, and high resistance damage from multiple cycles at high temperatures to name a few. The design is shown in figure 6a below with arrows indicating the key components of the system. For temperature measurement, a precision 5axis manipulator was designed to reproducibly aim a Mikron ${ }^{\mathrm{TM}}$ ISR50-LO 2-color pyrometer thru a 3mm diameter near black body port at a distance of $\sim 340 \mathrm{~mm}$, ensuring reliable temperature measurements. The pyrometer's measuring spot size is $1.7 \mathrm{~mm}$ and measures in the infrared (IR) spectrum in the ranges of 0.9 and $1.05 \mu \mathrm{m}$. Figure $6 \mathrm{~b}$ is a photo of the actual system housed inside a water-cool controlled atmosphere chamber which allow operation under vacuum or with an inert atmosphere. 


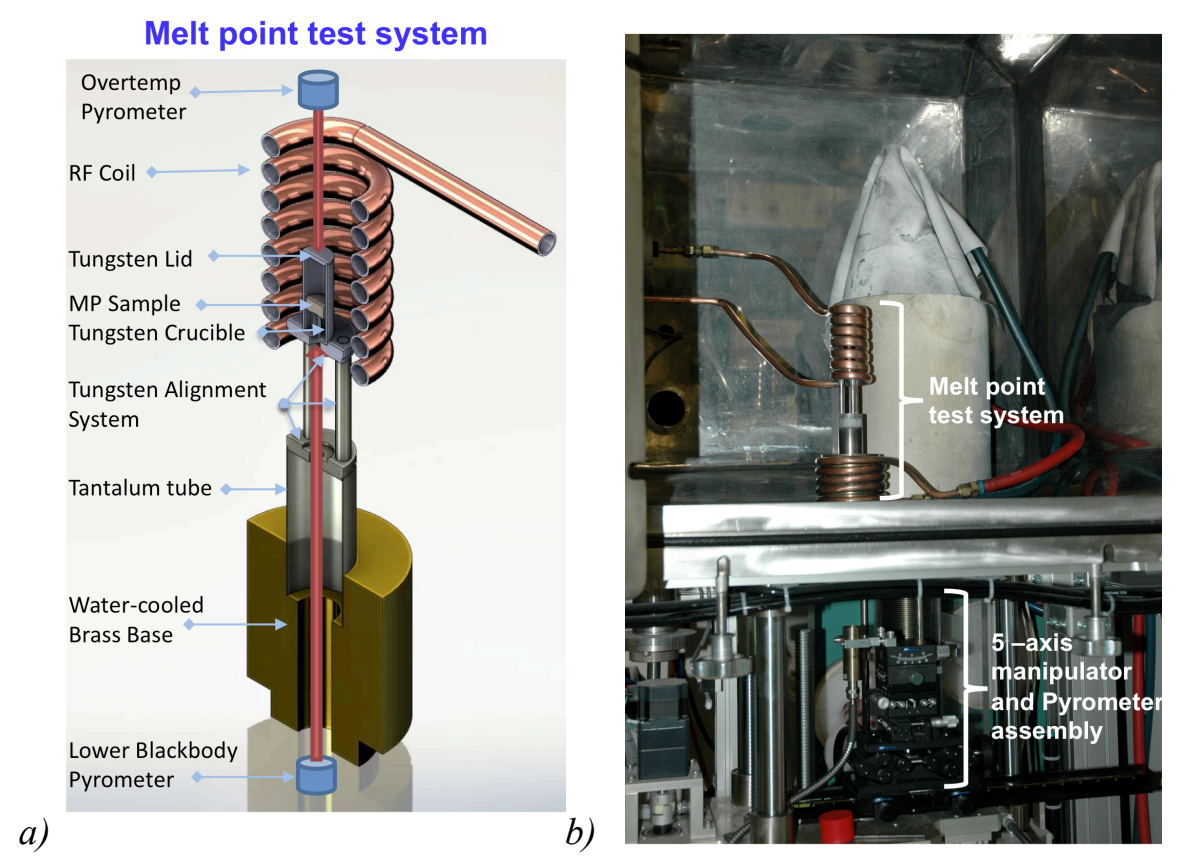

Figure 6(a,b). Figure 6a shows a 3-D sectional rendering of the melt point system heating assembly used in the melt point determination experiments and figure $6 \mathrm{~b}$ is a photo of the actual system.

Measurements in this study were performed under a slight vacuum with a partial pressure of argon- $6 \%$ hydrogen $(\mathrm{Ar} / 6 \% \mathrm{H})$ gas mixture. This atmosphere was chosen to prevent oxidation of the melt point assembly. Due to the large melt point variation associated with $\mathrm{O} / \mathrm{M}$, control of oxygen partial pressure over the sample as it is melted must be maintained to provide a known stoichiometry and produce meaningful datasets. The power supply used was an Ameritherm Inc. Ekoheat 45/100 power supply providing $45 \mathrm{~kW}$ of power and operating between 50 and $150 \mathrm{kHz}$.

\subsection{System Testing}

\subsubsection{System validation tests}

To verify that the LANL melt point system could be used to reliably determine the melting points of high temperature materials, a series of validation test were performed. The tests were performed on high melting point materials that had been extensively studied in the past, therefore reliable melt point data sets were available for comparison. The materials chosen for evaluation were Niobium ( $\mathrm{Nb}$ ), Molybdenum (Mo) and Hafnia $\left(\mathrm{HfO}_{2}\right)$. An interesting note is that $\mathrm{HfO}_{2}$ has two polymorphs that appear before melting. These polymorphs include a tetragonal phase at $1830^{\circ} \mathrm{C}$ and a cubic phase at $2520^{\circ} \mathrm{C}$. This temperature behavior is shown in the phase diagram by $\mathrm{Wu}$ et al. [11] and shown in figure 7 below. 


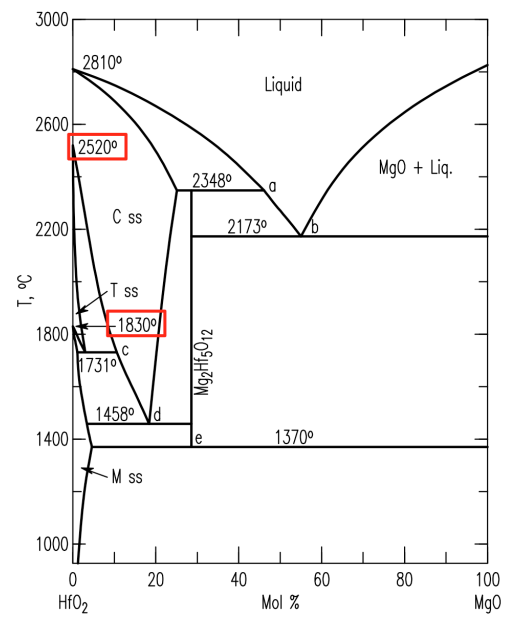

Figure 7. A Binary phase diagram of $\mathrm{HfO}_{2}-\mathrm{MgO}$ showing the monoclinic to tetragonal and the tetragonal to cubic transformation temperatures highlighted with red boxes.

In an attempt to test the sensitivity of the melt point system a melt point experiment was performed on $\mathrm{HfO}_{2}$ in order to measure the monoclinic to tetragonal (m-t), tetragonal to cubic (t-c) and melting point of the material. The results of the experiment are shown in the heating curves in figure $8 \mathrm{a}$ and $8 \mathrm{~b}$. For clarity the regions of interest are shown in different plots. In figure 8a, the plot shows the region in which the $\mathrm{m}-\mathrm{t}$ and $\mathrm{t}-\mathrm{c}$ transformations are found. As can be seen on $8 \mathrm{a}$, both the $\mathrm{m}-\mathrm{t}$ and $\mathrm{t}-\mathrm{c}$ transformation temperatures are resolved in the heating curves. Figure $8 \mathrm{~b}$ shows the region in which we observed the onset of melting of the material. Table 1 summarizes our results and compares them to the values from the $\mathrm{HfO}_{2}-\mathrm{MgO}$ phase diagram.
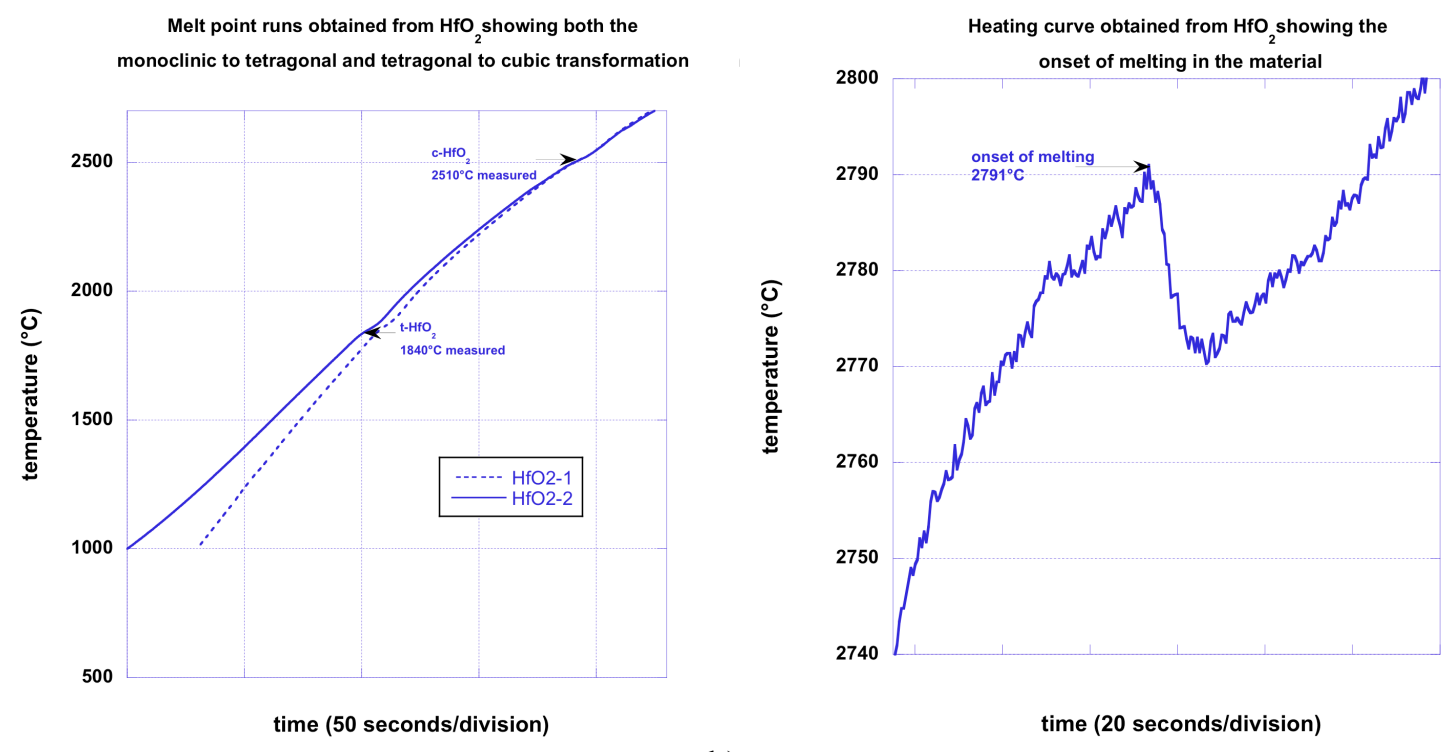

a)

b)

Figure 8(a,b) Figure 8a shows heating curve plots obtained from two independent tests showing the temperatures in which the $\mathrm{m}-\mathrm{t}$ and $\mathrm{t}-\mathrm{c}$ transformations occur. Figure $8 \mathrm{~b}$ shows the result of a melt point 
determination test. Results from both series of tests are in good agreement with the reported literature values.

Table 1. Tabulated values from the literature and measured data comparing of the transformation and melting temperatures.

\begin{tabular}{|l|l|l|l|}
\hline & $\begin{array}{l}\text { m-t transformation } \\
\text { temperature }\end{array}$ & $\begin{array}{l}\text { t-c transformation } \\
\text { temperature }\end{array}$ & $\begin{array}{l}\text { Onset of melting } \\
\text { temperature }\end{array}$ \\
\hline Wu et al. values & $1830^{\circ}$ & $2520^{\circ} \mathrm{C}$ & $2810^{\circ} \mathrm{C}$ \\
\hline Measured values & $1840^{\circ} \mathrm{C}$ & $2510^{\circ} \mathrm{C}$ & $2791^{\circ} \mathrm{C}$ \\
\hline
\end{tabular}

It can be easily seen from table 1 that for these literature values, the measured values compare favorably and are well within the range including the $+/-1 \%$ error of the pyrometer.

In order to further assess the melt point system, several more melt point determination experiments were performed on Niobium ( $\mathrm{Nb}$ ) and Molybdenum (Mo) metal samples. Metals were chosen mainly due to their established melt point values. The literature values we chose to use for comparison were from the CRC handbook of Chemistry and Physics [12] which lists the melting points as $2633^{\circ} \mathrm{C}$ for Mo and $2477^{\circ} \mathrm{C}$ for $\mathrm{Nb}$ respectively. Figure 9 shows the heating curve plots for 4 melt point experimental runs. The plots show the onset of melting temperatures for both $\mathrm{Mo}$ and $\mathrm{Nb}$ and the position on the $\mathrm{y}-$ temperature axis where the $\mathrm{CRC}$ values belong. From observation of the plot it can be seen that the measured values are in good agreement with the literature values.



Figure 9. Heating curve plots obtained from four ( 2 on Mo and 2 on $\mathrm{Nb}$ ) melt point determination experiments. The averaged measured values compare well with the [12] melt point values, specifically for $\mathrm{Mo}_{\text {measured }}-2619^{\circ} \mathrm{C}$ ) vs. $\mathrm{Mo}_{[12]^{-}}-2623^{\circ} \mathrm{C}$ and $\mathrm{Nb}_{\text {measured }}-2486^{\circ} \mathrm{C}$ vs. $\mathrm{Nb}_{[12]^{-}}-2477^{\circ} \mathrm{C}$. 


\subsection{Experimental test specimen fabrication details}

\subsubsection{Fabrication of pseudo binary U-Ce-O and U-Nd-O test materials}

In preparation for melt point determination experiments, materials were synthesized for thermophysical property measurements and pellet fabrication advancement studies were obtained. The materials consisted of urania, urania-ceria and urania-neodymia compounds. Two compositions ${ }^{\dagger}$ of urania-ceria $\left(\mathrm{U}_{0.95} \mathrm{Ce}_{0.05} \mathrm{O}_{2+\mathrm{x}}\right.$ and $\left.\mathrm{U}_{0.80} \mathrm{Ce}_{0.20} \mathrm{O}_{2+\mathrm{x}}\right)$ and urania-neodymia $\left(\mathrm{U}_{0.95} \mathrm{Nd}_{0.05} \mathrm{O}_{2+\mathrm{x}}\right.$ and $\left.\mathrm{U}_{0.80} \mathrm{Nd}_{0.20} \mathrm{O}_{2+\mathrm{x}}\right)$ were synthesized at Oak Ridge National Laboratory (ORNL), in addition to a urania baseline sample. All samples were made by the Modified Direct Denitration (MDD) process developed at ORNL [13-14]. These materials were treated to a stoichiometric condition using ASTM standard C1430-07 as a basis for determination of a stoichiometric oxygen-to-metal ratio $(\mathrm{O} / \mathrm{M})$ for each of the compositions [15].

\subsubsection{Reduction of Urania and Urania-compounds}

Materials for melt point determination were received from ORNL in an oxidized state with higher than the desired stoichiometry. To provide a uniform test basis and allow comparison of future data sets, the materials were reduced to a stoichiometric condition by treating them in an $\mathrm{O} / \mathrm{M}$ furnace. The materials were each pelletized in a $13 \mathrm{~mm}$ Spex single action die and pressed to an approximate density of $35 \%$ of the theoretical density (TD) based on a stoichiometric condition. The materials were then treated with a wet argon- $6 \%$ hydrogen gas mix for 6 hours in a tube furnace to set the proper oxygen partial pressure above the pellets to achieve a stoichiometric condition. The pellets were then crushed, ground and sieved through a -200 mesh $(-74 \mu \mathrm{m})$ screen in preparation for pelletization.

\subsubsection{Pelletization of stoichiometric Urania and Urania-compounds}

Urania and urania-compounds with stoichiometric compositions were prepared for melt point testing by pelletizing and sintering to achieve a dense robust pellet with mechanical integrety for loading into the melt point crucibles. Materials were pressed to a density of approximately $40 \% \mathrm{TD}$ in a $13 \mathrm{~mm}$ die and subsequently sintered in a metal furnace on tungsten fixturing at $1550^{\circ} \mathrm{C}$ in an atmosphere of gettered argon for 4 hours followed by a reduction step at $800^{\circ} \mathrm{C}$ in a reducing environment in an attempt to set the stoichiometry of the pellets at 2.00:1 (O/M).

\subsection{Experimental details and results obtained from measurements of $\mathrm{U}_{2.00}, \mathrm{U}-\mathrm{Ce}-\mathrm{O}$ and $\mathrm{U}-\mathrm{Nd}-\mathrm{O}$}

\subsubsection{Experimental details and conditions}

Pelletized specimens (in the range of 2-4 g) were placed inside the tungsten crucible as labeled and shown in figure 6a. A tungsten lid was then placed on top and the entire assembly is loaded into the watercooled chamber shown in figure $6 \mathrm{~b}$. It should be noted that the crucible containing the samples were not

$\dagger \quad$ These were the initial calculated compositions, it must me noted that the materials may have compositions that deviated slightly from the stated values during the processing regimen. These compositions were used as initial test specimens, full characterization was beyond the scope of this report. The next series of samples intended to provide publication quality data will undergo full characterization before and after melt determination experiments. 
hermetically sealed in the experiments presented below. We are aware that since the crucibles are not sealed the samples may change in composition during melt point experiments, therefore we only performed one full melt per experiment followed by a rapid cool down to attempt to minimize changes in composition. Samples can then characterized for possible changes in composition that may have occured then evaluated against the measured melt to determine the validity of each experiment. After the sample/assembly is placed inside the chamber, the chamber is evacuated followed by a backfill of $\mathrm{Ar} / 6 \% \mathrm{H}$, then re-evacuated followed by another backfill of $\mathrm{Ar} / 6 \% \mathrm{H}$. The final atmosphere therefore is a slight vacuum with a partial pressure of $\mathrm{Ar} / 6 \% \mathrm{H}$ gas mixture. This atmosphere was chosen mainly to suppress oxidation of the tungsten parts the system is fabricated from. The experiments were performed by programming a voltage versus time ramp in the voltage supply that supplies power to the induction coil, thereby heating the specimen capsule. During the experiment, the power input profile is also logged and is superimposed with the programmed voltage profile in figure 10 below. The temperature of the sample being melted is monitored through a black body cavity as a function of time/voltage (or power), and collected via a data acquisition program. Additionally, the temperature of the top of the sample capsule is also monitored during the experiment which typically shows $\sim 100^{\circ} \mathrm{C}$ greater than the blackbody measurement.

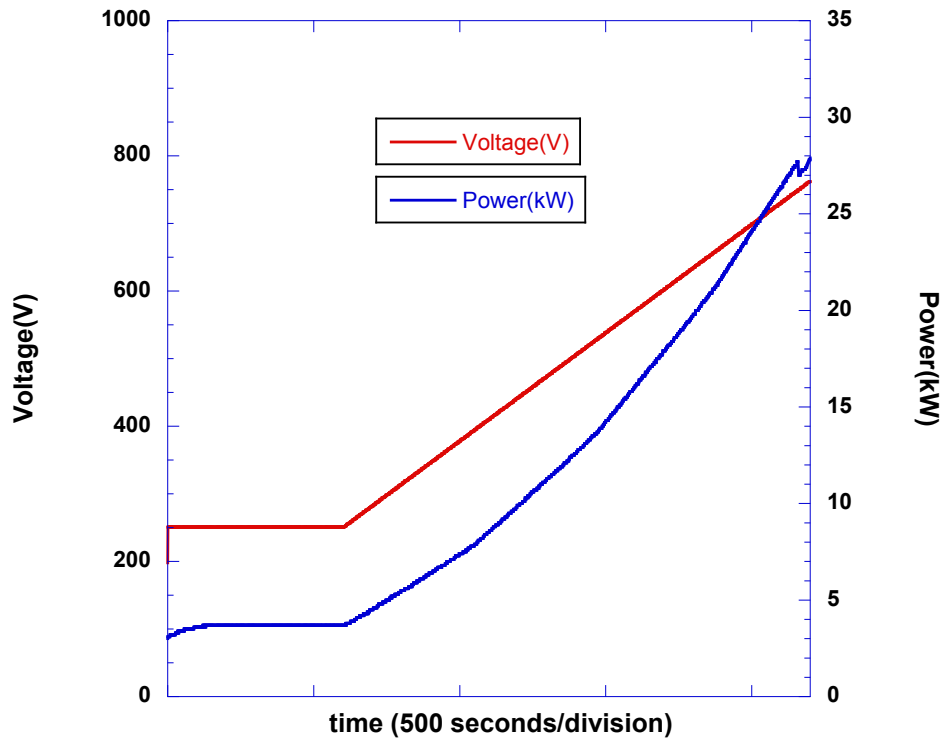

Figure 10. A typical experimental voltage (power) heating profile used during melt point determination experiments.

\subsubsection{Experimental results obtained from measurements of $\mathrm{UO}_{2.00}$ and $\mathrm{U}-\mathrm{Ce}-\mathrm{O}$ pseudo binaries}

A series of three separate melt point determination experiments were performed using the conditions outlined in section 2.4.1 on $\mathrm{UO}_{2.00}, \mathrm{U}_{0.95} \mathrm{Ce}_{0.05} \mathrm{O}_{2.00}$ and $\mathrm{U}_{0.80} \mathrm{Ce}_{0.20} \mathrm{O}_{2.00}$. From these experiments, it was found that the measured melting point of the pure $\mathrm{UO}_{2.00}$ was $2845^{\circ} \mathrm{C}$ which upon comparing to the average value of $2857^{\circ} \mathrm{C}$ from the measurements in figure 1 shows a very good agreement with published data. The measured melt points of both $\mathrm{U}_{0.95} \mathrm{Ce}_{0.05} \mathrm{O}_{2.00}$ and $\mathrm{U}_{0.80} \mathrm{Ce}_{0.20} \mathrm{O}_{2.00}$ were measured as $2630^{\circ} \mathrm{C}$ and $2555^{\circ} \mathrm{C}$ respectively. Although the trend of decreasing melting point as a function of adding a lower melting point miscible compound $\left(\mathrm{CeO}_{2}\right)$ to a higher melting point compound $\left(\mathrm{UO}_{2}\right)$ as in our system is correct as illustrated in binary phase diagrams, the accuracy of the measured data points for the stated material stoichiometry may be slightly off. This data could not be verified by comparison with published values due the fact that none were found during our literature survey. Therefore it must be stated that 
these are only tentative results that can only be fully accepted after performing detailed characterization of the test specimens before and after melt point experiments. Results from the melt point experiments on $\mathrm{UO}_{2.00}$ and both $\mathrm{U}-\mathrm{Ce}-\mathrm{O}$ specimens are shown below in figure 11 .

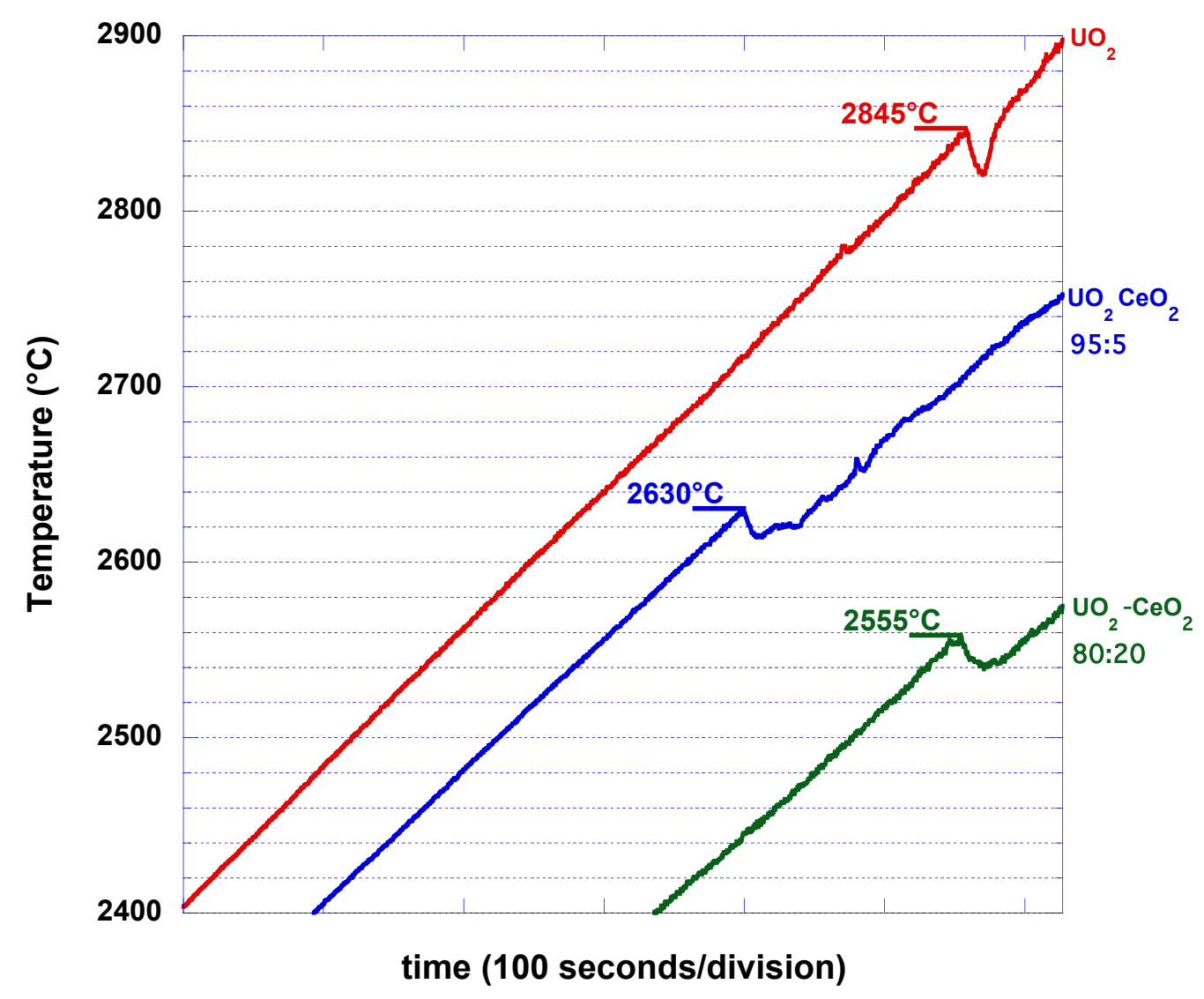

Figure 11. Heating curves collected during melting point experiments on $\mathrm{UO}_{2.00}$ and the U-Ce-O test specimens.

\subsubsection{Experimental results obtained from measurements of $\mathrm{UO}_{2.00}$ and $\mathrm{U}-\mathrm{Nb}-\mathrm{O}$ pseudo binaries}

A series of three separate melt point determination experiments were performed using the conditions outlined in section 2.4.1 on $\mathrm{UO}_{2.00}, \mathrm{U}_{0.95} \mathrm{Nd}_{0.05} \mathrm{O}_{2.00}$ and $\mathrm{U}_{0.80} \mathrm{Nd}_{0.20} \mathrm{O}_{2.00}$. It was found that the measured melting point of the pure $\mathrm{UO}_{2.00}$ was $2846^{\circ} \mathrm{C}$ which upon comparing to the average value of $2857^{\circ} \mathrm{C}$ from the average value of $2857^{\circ} \mathrm{C}$ in figure 1 shows a very good agreement with the published data. The measured melt points of both $\mathrm{U}_{0.95} \mathrm{Nd}_{0.05} \mathrm{O}_{2.00}$ and $\mathrm{U}_{0.80} \mathrm{Nd}_{0.20} \mathrm{O}_{2.00}$ were measured as $2806^{\circ} \mathrm{C}$ and $2780^{\circ} \mathrm{C}$ as shown in figure 12. For comparison, melting points from material with similar stoichiometries were extracted from the $\mathrm{UO}_{2}-\mathrm{Nd}_{2} \mathrm{O}_{3}$ phase diagram shown in figure 13, published by Lambertson et al. [16] in 1954. Data from our melt point measurements compared with the values obtained from the phase diagram in Lambertson et al. are shown in Table 2. When comparing the published values to the values acquired from our measurements, it can be seen that for the first two measurements on $\mathrm{UO}_{2}$ and $\mathrm{U}_{0.95} \mathrm{Nd}_{0.05} \mathrm{O}_{2.00}$ the values differ by $30^{\circ} \mathrm{C}$ and $24^{\circ} \mathrm{C}$, respectively which is well in the range of the $1 \%$ error in our pyrometer. On the other hand the published value compared to our measured value for $\mathrm{U}_{0.80} \mathrm{Nd}_{0.20} \mathrm{O}_{2.00}$ varies by $217^{\circ} \mathrm{C}$. As seen in the previous measurements on $\mathrm{UO}_{2.00}$ and $\mathrm{U}-\mathrm{Ce}-\mathrm{O}$ the $\mathrm{UO}_{2.00}$ and U-Nd-O data also clearly shows a trend of decreasing melting point as a function of adding a lower 
melting point miscible compound $\left(\mathrm{Nd}_{2} \mathrm{O}_{3}\right)$ to a higher melting point compound $\left(\mathrm{UO}_{2}\right)$ as in our system which is the same trend illustrated in binary phase diagrams, the accuracy of the measured data points for the stated material stoichiometries may be slightly off due to processing and changes in the material composition during the melt point experiment. Therefore the latter issues can lead to inaccurate melt points for a stated composition. Future experiments will focus on detailed characterization before and after melting experiments as well as refining a crucible design to prevent changes in $\mathrm{O} / \mathrm{M}$ and oxidations states in materials being tested.

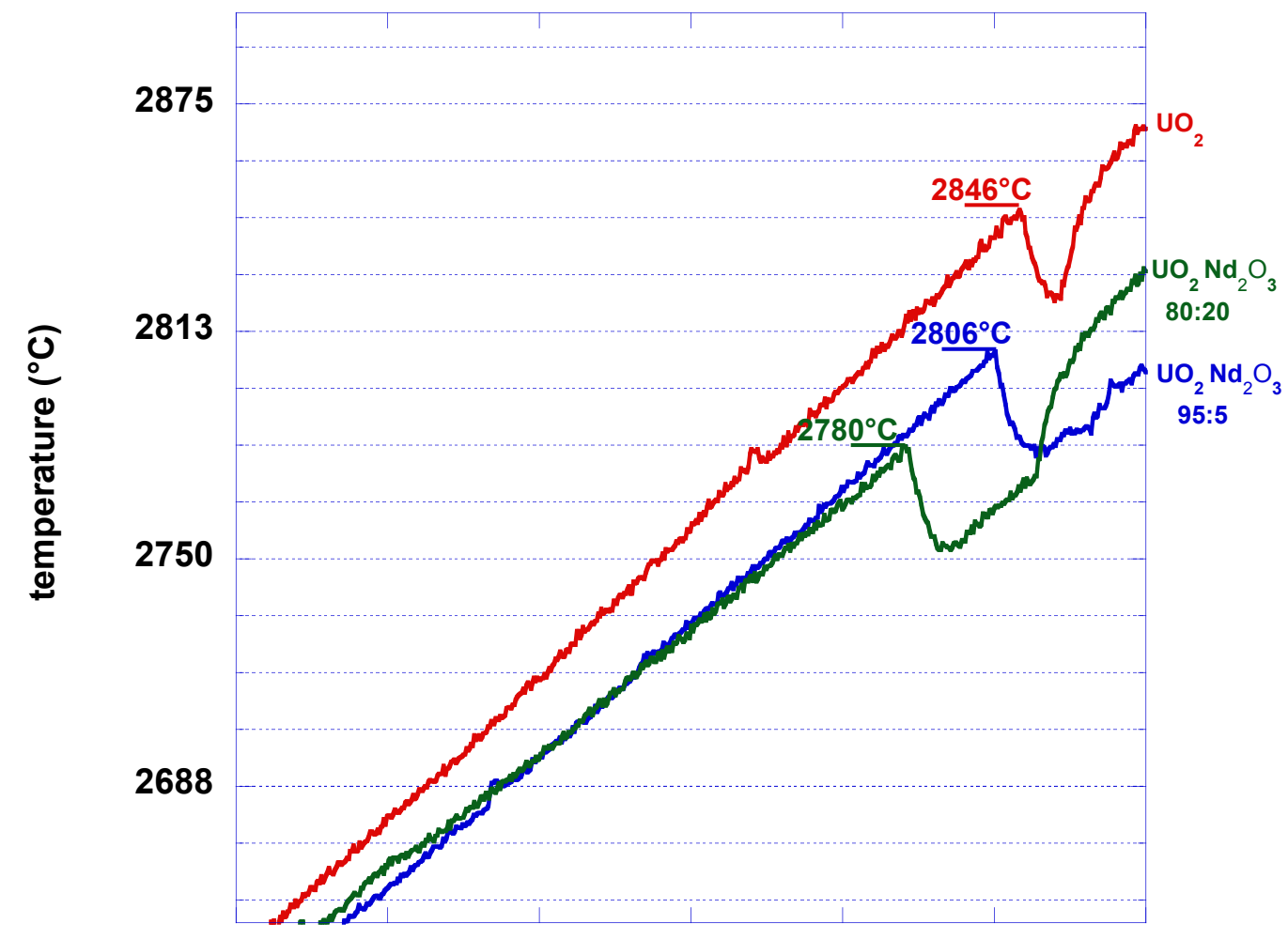

time (50 seconds/division)

Figure 12. Heating curves collected during melting point experiments on $\mathrm{UO}_{2.00}$ and the U-Nd-O test specimens. 


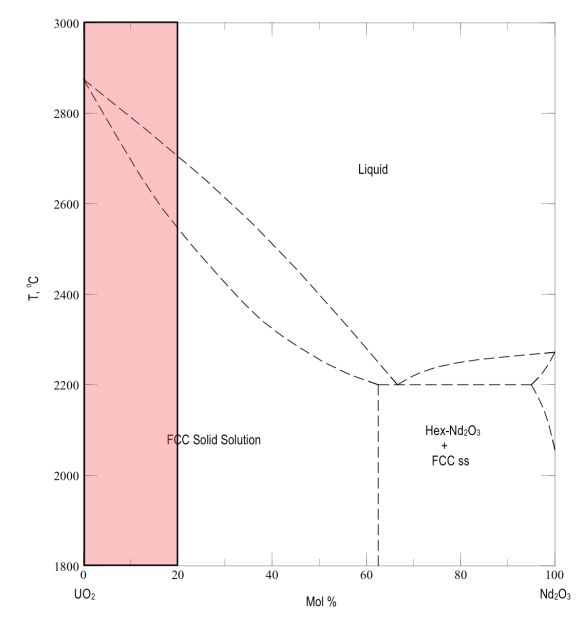

Figure 13. Plot of a binary phase diagram showing the solubility of $\mathrm{Nd}_{2} \mathrm{O}_{3}$ in $\mathrm{UO}_{2}$. The phase diagram has a highlighted region in the composition range in which samples were measured in fulfillment of this report.

Table 2. Table comparing literature values obtained from [16] with measure value collect during this investigation. The last row shows the difference between the two sets of values.

\begin{tabular}{|l|l|l|l|}
\hline & $\mathbf{U O}_{2}$ & $\mathbf{U}_{\mathbf{0 . 9 5}} \mathbf{N d}_{\mathbf{0 . 0 5}} \mathbf{O}_{2.00}$ & $\mathbf{U}_{\mathbf{0 . 8 0}} \mathbf{N d}_{\mathbf{0 . 2 0}} \mathbf{O}_{\mathbf{2 . 0 0}}$ \\
\hline Published values, [16] & $2876^{\circ} \mathrm{C}$ & $2782^{\circ} \mathrm{C}$ & $2563^{\circ} \mathrm{C}$ \\
\hline Measured data & $2846^{\circ} \mathrm{C}$ & $2806^{\circ} \mathrm{C}$ & $2780^{\circ} \mathrm{C}$ \\
\hline $\begin{array}{l}\text { Difference between } \\
\text { literature and } \\
\text { measured values }\end{array}$ & $30^{\circ}$ & $24^{\circ} \mathrm{C}$ & $-217^{\circ} \mathrm{C}$ \\
\hline
\end{tabular}

\section{Summary}

The development and validation of a ceramic melt point determination system able to test materials with melting points up to $3000^{\circ} \mathrm{C}$ was completed. A series of benchmark tests on three material systems were performed as well as measurements on of $\mathrm{U}_{2.00}, \mathrm{U}-\mathrm{Ce}-\mathrm{O}$ and $\mathrm{U}-\mathrm{Nd}-\mathrm{O}$ pseudo-binary materials supplied by ORNL. The following is a bulleted list of the achievements associated with successfully completing this milestone:

- LANL successfully designed a system to withstand the high temperatures associated with this material property characterization technique.

- A precision 5-axis translation fixture was developed to aim the primary temperature measurement pyrometer. This development was key in being able to perform precision adjustments to aim the pyrometer into the black body cavity on the crucible for accurate and reproducible temperature measurements. 
- A series of benchmarking validation tests were performed on $\mathrm{Mo}, \mathrm{Nb}$ and $\mathrm{HfO}_{2}$ and showed the system is able to accurately measure high melting point materials and produce temperature values in close agreement with the literature.

- The $\mathrm{UO}_{2.00}$ melt point was measured and corresponded well with values published in literature reports.

- Measurements were performed on $\mathrm{UO}_{2.00}, \mathrm{U}_{0.95} \mathrm{Ce}_{0.05} \mathrm{O}_{2.00}$ and $\mathrm{U}_{0.80} \mathrm{Ce}_{0.20} \mathrm{O}_{2.00}$. The generally trend of decreasing melt point as a function of composition corresponds with the measurements.

- Measurements were performed on $\mathrm{UO}_{2.00}, \mathrm{U}_{0.95} \mathrm{Nd}_{0.05} \mathrm{O}_{2.00}$ and $\mathrm{U}_{0.80} \mathrm{Nd}_{0.20} \mathrm{O}_{2.00}$. For $\mathrm{UO}_{2.00}$ and $\mathrm{U}_{0.95} \mathrm{Nd}_{0.05} \mathrm{O}_{2.00}$, comparing the measured values to literature values shows good correlation. For all samples, the general trend showing decrease in melt point as a function of composition corresponds well with the expected behavior of binary solid solutions as a function of temperature.

Several outstanding issues remain to be resolved to improve the handling of materials and quality of the melt point data. These include:

- Developments of a test methodology to fully characterize test specimens before and after melt point determination experiments. This will aid in decreasing the error in measurements, thus providing accurate datasets to be used in predictive models for research and development of efficient and accident tolerant fuels.

- Adapt a methodology to hermetically seal samples in measurement crucibles to minimize deleterious effects that change the samples, resulting in random changes in the melt point values. These effects include oxidation/reduction, changes in valence and phase separation. Additionally, new crucible materials need to be researched to help minimize sample/crucible interaction, which can lead to unpredictable changes in the melt point of the starting material.

- Develop dynamically controlled software, allowing precise temperature control within narrow ranges of material melt point values leading to higher precision measurements.

\section{References}

1) Bates J.L., JNM 36, (1970), 195-210.

2) Latta R.E., Fryxell R.E., JNM 35, (1970), 195-210.

3) Komatsu J., Tachibana T., Konashi K., JNM 154, (1988) 38-44.

4) Christensen J.A., United States Report, HW-69234, (1962).

5) Christensen J.A., Tans. Amer. Nucl. Soc. 7, (1964), 390.

6) Kono K., Hirosana T., J. Nucl. Sci. Tech. 36, No.7, 596-604.

7) Riley B., J. Sci. Instrum. 41, (1964), 504-507.

8) Kato M., Morimoto K., Sugata H., J. of Alloys and Comp. 452, iss. 1, (2008), 48-53.

9) Kato M., Morimoto K., Sugata H., Konashi K., Kashimura M., JNM 373, (2008), iss. 1-3, $237-$ 245.

10) Reed T.B., Foley R.E., Strauss A.J., J. Cryst. Growth 15, iss.3, (1972), 174-178 
11) K. S. Wu and Z. P. Jin, CALPHAD: Comput. Coupling Phase Diagrams Thermochem., 21 [3] 411-420 (1997).

12) CRC Handbook of Chemistry and Physics. 81st ed. CRC Press: Boca Raton, FL, 2000-2001

13) Haas P.A., Arthur R.D., "Development of Thermal Denitration to Prepare Uranium Oxide and Mixed Oxides for Nuclear Fuel Fabrication”, ORNL-5735, Oak Ridge National Laboratory, Oak Ridge, Tennessee (1981).

14) Felker, L.K., Vedder, R.J., Walker, E.A., Collins, E.D., "Product Conversion: The Link between Separations and Fuel Fabrication", Atalante 2008: Nuclear fuel cycle for a sustainable future, Montpellier (France), 19-23 May 2008.

15) ASTM Standard C1407, 2007 (2011), " Standard Test Method for Determination of Uranium, Oxygen to Uranium $(\mathrm{O} / \mathrm{U})$, and Oxygen to Metal $(\mathrm{O} / \mathrm{M})$ in Sintered Uranium Dioxide and Gadolinia-Uranium Dioxide Pellets by Atmospheric Equilibration," ASTM International, West Conshohocken, PA, 2011, DOI: 10.1520/C1430-07R11E01, www.astm.org.

16) W. A. Lambertson and M. H. Mueller, United States Atomic Energy Commission, U.S.A.E.C. Report No.ANL-5312, National Technical Information Service; Springfield, Virginia, September $14,1954$. 